\title{
Las milicias guaraníes en el Paraguay y Río de la Plata: alcances y limitaciones (1649-1756)
}

\author{
MERCEDES AVELLANEDA* \\ LÍA QUARLERI**
}

\begin{abstract}
Resumo: O presente trabalho procura dar conta do impacto da criação de milícias guaranís na configuração geopolítica e socioeconômica das fronteiras rio-platenses, durante os séculos XVII e parte do XVIII. Partimos do pressuposto de que as fronteiras surgem historicamente pela articulação de interesses, ações e sentidos atribuídos pelos atores locais e pelos poderes centrais. Seguindo esta orientação, por um lado, analisaremos a influência situacional do exército missioneiro nos principais conflitos fronteiriços e políticos originados pelos governos do Paraguai e de Buenos Aires, bem como seu alcance e suas limitações na relação com a dinâmica geopolítica regional. Por outro lado, interesa mostrar o impacto dos privilégios obtidos pelas reduções jesuíticas sobre outros setores sociais bem como os efeitos negativos de sua condição de milícias do rei sobre a vida missioneira.
\end{abstract}

\begin{abstract}
The present research tries to show the impact that the creation of the guaraníes militias had on the geopolitical and socioeconomic platenses frontiers, during the XVII and part of the XVIII centuries. We start from the idea that the frontiers were historically formed by the articulation of interests, action and meanings given by the local actors and the central powers. According to this concept, we are going to analyze the situational influence of the missionary army on the main bordering and political conflicts originated in the governments of Paraguay and Buenos Aires and we are also taking into account their achievements and limitations in relation to geopolitical regional dynamic. On the other hand, it is interesting to point out the impact of the privileges obtained by the Jesuit Missions and the negative effects that the condition of "milicias del Rey" brought to the missionary life.
\end{abstract}

Palavras-chave: Milícias guaranis. Missões jesuíticas. Guerras de fronteiras.

Key words: Guarani militias. Jesuit missions. Frontier wars.

Sección Etnohistoria. Facultad de Filosofía y Letras. Universidad de Buenos Aires. Email: bocca@fibertel.com.ar

* Sección Etnohistoria. Facultad de Filosofía y Letras. Universidad de Buenos Aires CONICET. E-mail: liaquarleri@yahoo.com.ar

Estudos Ibero-Americanos. PUCRS, v. XXXIII, n. 1, p. 109-132, junho 2007 


\section{Introducción}

A principios del siglo XVII, los asunceños habían fundado, en el Paraguay y Río de la Plata, varias ciudades y pueblos de indios aledaños. El territorio ocupado recortaba una amplia frontera difícil de defender de los distintos grupos indígenas rebeldes. A ello se sumaban los portugueses que aliados con los tupies emprendían entradas periódicas de captura para alimentar el comercio de esclavos en la capitanía de San Vicente del Brasil. La principal riqueza en disputa eran los numerosos grupos indígenas que habitaban las provincias de Itatim, Guayrá, Paraná, Uruguay y el Tapé y que algún día podían ser encomendados por los españoles o esclavizados por los bandeirantes que los trasladaban al territorio de la Corona portuguesa. La fundación de las primeras reducciones jesuitas respondió al plan instrumentado por el gobernador Hernandarias y el obispo Ignacio de Loyola, para reforzar la presencia española en esa vasta frontera y defender a los pueblos de indios reducidos mediante la creación de misiones. Con el apoyo inicial de los vecinos, los jesuitas fundaron sus primeras reducciones en las provincias del Guayrá, Itatim y Paraná con pueblos de indios de encomiendas y luego en territorios habitados por tribus hostiles. Gracias a las Ordenanzas de Alfaro, pudieron establecer con los caciques, una alianza para liberarlos momentáneamente del servicio personal y defenderlos de los bandeirantes e indios enemigos con el auxilio de armas de fuego. El éxito de esta alianza inicial radicó en el mayor poder defensivo de los cacicazgos al reagruparlos en un mismo poblado y al ejercitarlos de forma progresiva en las tácticas de guerra española. ${ }^{1}$

A esta primera etapa, le siguió una segunda de expansión del sistema misional en las décadas de 1620 y 1630. Esta se caracterizó por la fundación de numerosas reducciones en los confines de la frontera configurada tanto en el Guayrá como en el Paraná, Uruguay y Tapé. Frente a esta nueva ocupación efectiva de la frontera española, los portugueses reaccionaron con una guerra ofensiva de penetración territorial por medio de numerosas bandeiras y decidieron atacar las misiones en sus diferentes enclaves. ${ }^{2}$ El resultado fue el despoblamiento primero del Guayrá, luego de los Itatim y finalmente del Tape por la destrucción de sus reducciones y su reconcentración en las provincias del Paraná y Uruguay. Todo ello provocó la liberación de los caminos de la costa para nuevas en-

1 Este tema ha sido investigado en Avellaneda (1999).

2 Al menos 18 incursiones de los bandeirantes principalmente al Guayrá y a la región del Tape e Itatim, desde 1602 hasta 1641, son mencionadas por Alfredo Ellis (1934). 
tradas de bandeirantes, la perdida de los pueblos de encomienda de Santiago de Xerez y su posterior despoblamiento, el traslado de Villa Rica más cerca de Asunción, y el avance de los grupos chaqueños sobre las tierras abandonadas. Con la retractación de la frontera del norte y del este, se intensificaron los asaltos indígenas en las cercanías de Asunción durante la segunda mitad del siglo XVII y se produjo el despoblamiento de una importante área rural. Los pueblos de indios de Atirá, Ypané y Guarambaré fueron trasladadas hacia el sur de la ciudad, las tierras ocupadas por la población rural al norte del río Monduvirá fueron abandonadas y la explotación de numerosos yerbales quedó suspendida al despoblarse los puertos sobre el río Jejui y los pueblos de indios yerbateros. Las tierras al sur de Asunción fueron abandonadas y la población rural se reagrupó en las cercanías de los fuertes, de los pueblos de indios de encomiendas y de las doctrinas.

En el Paraná y Uruguay la concentración defensiva de las reducciones y su entrenamiento militar representó una estrategia para enfrentar al enemigo y detener su avance sobre la región. El primer gran triunfo contra los portugueses lo alcanzaron las milicias jesuitas en la batalla de Mbororé en 1641 con un ejército de guaraníes entrenados por hermanos legos veteranos de las guerras de Flandes (Blanco, 1898, p. 231). Las reducciones para ese entonces contaban con un número importante de bocas de fuego, cañones de tacuara y canoas livianas para enfrentar al enemigo y luchaban con un ejército comandado por sus caciques que utilizaban "arcabuces, flechas, alfanjes y rodelas, piedras y machetes según la distinción de su milicia".3 Durante la década de 1640, las negociaciones emprendidas por el Padre Ruiz de Montoya, ante el Consejo de Indias y luego ante el Virrey, permitieron obtener el permiso de usar armas de fuegos en las reducciones y alcanzar el reconocimiento oficial que elevaba las milicias al servicio del Rey. En recompensa por la defensa y vigilancia de la frontera el Virrey eximía, en 1649, a los indios guaraníes de la mita y autorizaba el pago de tributo en un peso de a ocho reales, por año, al desempeñar las reducciones la función de presidios de frontera o enclaves militares. Una vez constituidas las milicias serían convocadas por los gobernadores de Buenos Aires y Paraguay, con

3 Un indicio claro sobre la posible organización militar en las reducciones la tenemos a partir de la declaración de dos caciques de Yapeyú ordenada por el gobernador del Río de la Plata, Don Pedro de Baigorri sobre los sucesos ocurridos con los portugueses cerca de sus reducciones en 1653 (Biblioteca Nacional de Río de Janeiro, Colección Pedro de Angelis, Documento № 392). 
diferente respuesta por parte de los jesuitas, para auxiliar la defensa del territorio en sus diferentes frentes.

En este trabajo buscamos dar cuenta del impacto de la creación de las milicias guaraníes en la configuración geopolítica y socio-económica de las fronteras platenses, durante el siglo XVII y parte del XVIII. Partimos de la idea que las fronteras se configuran históricamente por la articulación de intereses, acciones y sentidos dados por los actores locales y los poderes centrales. Siguiendo esta línea, por un lado, analizaremos la influencia situacional del ejército misionero en los principales conflictos fronterizos y políticos suscitados en las gobernaciones de Paraguay y Buenos Aires así como sus alcances y limitaciones en relación con la dinámica geopolítica regional. Por otro lado, nos interesa mostrar el impacto, en otros sectores sociales, de los privilegios obtenidos por las reducciones jesuíticas. Cabe aclarar dos cuestiones, una de ellas es que este trabajo se constituye en una primera aproximación a un tema que exige la consideración de un amplio eje temporal, coyuntural y un análisis situacional de la interacción social. La otra es que nos centraremos en los sucesos de máxima tensión y conflicto suscitados en los espacios mencionados.

\section{Gobernación de Paraguay}

En la gobernación del Paraguay (Asunción, Villa Rica, Santiago de Xerez, Ciudad Real), la defensa de las ciudades y de la campaña estaba principalmente a cargo de sus vecinos y pobladores, los cuales debían prestar servicio militar obligatorio y suministrar los recursos necesarios para las campañas militares. A su vez, los pueblos de indios encomendados a los españoles y criollos de Asunción y Villarrica y los “castillos” fundados, sobre el río Paraguay, para proteger la navegación, formaban parte de la estructura defensiva de la jurisdicción, la cual servía más para alertar sobre las incursiones de los indios enemigos que para contenerlas. En las chacras de los valles, que se encontraban alejadas de este escudo defensivo, sus pobladores vivían en estado de alerta permanente y su abandono dependía de los asaltos y de las treguas establecidas con las tribus enemigas. Los gobernadores cuando asumían se preocupaba en conocer las posibilidades reales defensivas con las que contaban y para ello acostumbraban realizar "alardes" y reseña de armas, en la ciudad y en los pueblos de indios. También se encargaban de mandar aderezar armas, fabricar municiones y canoas para la guerra. Ordenaban mejoras en la 
fortificación de la ciudad construyendo fuertes o arreglando los existentes y realizaban entradas al Chaco. Podían requerir la colaboración de las milicias guaraníes al Provincial de la Compañía de Jesús, pero la misma era sujeta a las buenas relaciones establecidas con los jesuitas locales y a las posibilidades de las reducciones. Por lo tanto, en la jurisdicción del Paraguay, las milicias guaraníes desempeñaron un papel relativo en la guerra defensiva contra los indios gentiles y los portugueses.

Podemos resumir la intervención de las milicias guaraníes en los siguientes aspectos:

\section{Suministro de soldados guaraníes para realizar entradas al} Chaco en castigo y persecución de guaycurues, payaguás y mbayás por los asaltos cometidos. Estos pedidos fueron bastante frecuentes porque los gobernadores realizaban siempre entradas punitivas en diferentes momentos. Las reducciones algunas veces colaboraban con una fuerza promedio de 200 soldados de apoyo, otras veces solamente con caballos, bastimentos y ganado. La ayuda de las milicias guaraníes debió competir, en alguna medida, con los intereses económicos de los encomenderos en la guerra. Por costumbre y pobreza de la tierra normalmente se financiaban los gastos de la defensa con permisos para realizar beneficios de yerba adjudicados por el gobernador al encomendero, lo que le permitían un posterior resarcimiento económico y vislumbrar una ganancia. También podían aspirar al botín de guerra en caballada o indios capturados.

Suministro de mano de obra indígena para la fortificación de los presidios, "castillos" y obras en la ciudad. Sabemos por el memorial del P. Jerónimo Herrán que la iglesia de Santa Lucia recibió ayuda de los guaraníes para su reconstrucción a pedido del gobernador Andrés Garabito de León y que también proveyeron de ayuda a la ciudad, en otras cinco oportunidades bajo el gobierno de Juan Diez de Andino. ${ }^{4}$ En tres oportunidades más se brindó ayuda para la fortificación del presidio de Tobaty, de San Idelfonso y de Arecutacua. En general los pueblos de indios eran los encargados de suministrar la mano de obra para todas las mitas requeridas. El descenso demográfico en estas poblaciones a principios del siglo XVIII era crítico.

Milicias guaraníes para combatir a los mamelucos. Estas tuvieron un éxito relativo para frenar el avance de los portugueses. En 1652 los bandeirantes invadieron la provincia del Paraguay,

4 Memorial del Padre Jerónimo Herrán, procurador general de la provincia del Paraguay, a su Majestad, año 1726 (Pastells, 1912, tomo VI, p. 473-481). 
con cuatro poderosas columnas, para llegar hasta Asunción y vaciarla de toda su población indígena. Paraguayos y jesuitas se unieron por primera vez al mando del gobernador Andrés de León Garabito y vencieron a los ejércitos invasores. En 1676 los portugueses volvieron a atacar los cuatro pueblos de indios de la ciudad de Villa Rica y sus pobladores debieron abandonarla al perder toda la mano de obra indígena. Según el memorial del Padre Herrán, 400 efectivos de las reducciones fueron suministrados a la ciudad para ir tras ellos y solo se consiguió recobrar unos pocos indios del pueblo de Mbaracayú. En 1688 las milicias guaraníes colaboraron nuevamente con el gobernador Francisco de Monforte, para expulsar a los bandeirantes. El despoblamiento de todo ese territorio obligó a los asuncenos a realizar salidas anuales de reconocimiento a los campos de Santiago de Xerez, para impedir que los portugueses se afincasen en esas tierras

Milicias guaraníes movilizada a pedido de un gobernador en resguardo de su persona o para hacer cumplir la voluntad del Virrey ante la resistencia armada de los asuncenos. En 1644, el gobernador Hinestroza utilizó 600 indios guaraníes de las reducciones para apresar al obispo Bernardino de Cárdenas por no reconocer su nombramiento y lo desterró de la Provincia. Mantuvo por mucho tiempo las milicias en la ciudad para hacerse obedecer por los vecinos. Al cabo de cuatro años el Obispo regresó y fue nombrado gobernador por voluntad popular en un cabildo abierto. En 1649, el virrey ordenó su comparecencia a la Audiencia de Charcas y para hacerlo cumplir por la fuerza, los jesuitas suministraron un ejército de 4000 efectivos al nuevo gobernador que se enfrentó a los partidarios del obispo con muchas muertes de ambos bandos. Como consecuencia de la intervención y las quejas de los vecinos, las milicias vieron confiscadas sus armas de fuego que solo les fueron devueltas en 1676 para combatir a los portugueses. Los asuncenos vencidos en el campo de batalla, a manos de indios bien "pertrechados" y en superioridad numérica, quedaron muy impresionados. En la memoria colectiva de la provincia se instaló desde entonces, una percepción negativa del ataque de las milicias jesuitas.

Desde el punto de vista geopolítico, podemos decir que las milicias guaraníes no lograron contener el avance de los bandeirantes y proteger las poblaciones españolas al norte y este de la frontera, ni tampoco fueron de mucha ayuda para frenar los asaltos de los indios del Chaco. La retractación de la frontera trajo el avance de los grupos infieles y obligó a los asuncenos a redoblar 
sus esfuerzos en la defensa de la provincia del Paraguay. La pérdida de pueblos de encomienda, yerbales y tierras de cultivo, provocó una crisis económica sin precedentes a partir de la segunda mitad del siglo XVII que se agravó con la depreciación de la yerba. El comercio de las reducciones representó una competencia desigual para los asuncenos por estar los religiosos exentos de todo tipo de impuesto. El beneficio de la yerba era considerado hasta entonces un privilegio exclusivo otorgado a los vecinos de Paraguay a cambio de sus esfuerzos en la defensa del territorio. ${ }^{5} \mathrm{Su}$ alto precio y extendida demanda convertirían a la yerba en el oro negro de la colonia. Los asuncenos estaban obligados a pagar numerosos impuestos: estanco, diezmo, alcabala, sisa, puerto preciso, a lo que se sumaba los largos fletes y mermas del acarreo, mientras que las reducciones contaban con el apoyo real para beneficiarse anualmente $12 \mathrm{mil}$ arrobas de yerba a un precio redituable. La economía paraguaya quedaba así estrangulada por la importante oferta de yerba volcada al mercado regional por las reducciones. El Consejo de Indias, más propenso a depositar su confianza en los jesuitas y su leal ejército, desoyó las quejas de los vecinos que reclamaban la exclusividad de ese privilegio o la supresión de algún impuesto. Con el tiempo la competencia desigual de las reducciones por la yerba, la mano de obra, la explotación de la tierra, el comercio, los privilegios adquiridos y la crisis económica, fueron preparando el escenario político para los enfrentamientos más violentos ocurridos entre las reducciones y los asunceños, a principios del siglo XVIII.

\section{La "Revolución de los Comuneros"}

Entre 1721 y 1735 la provincia de Paraguay fue el escenario de un importante movimiento socio-político que dividió en dos facciones antagónicas a la sociedad asuncena: "comuneros", por un lado, y los llamados "contrabandos", por el otro, y los enfrentó en episodios de extrema violencia. Los jesuitas y las milicias guaraníes, por su parte, se alinearon contra los comuneros y desempeñaron un rol protagónico en la restitución del orden colonial. Estas dos décadas de conflicto pueden resumirse en tres grandes momentos. En una primera etapa, el conflicto se desencadenó cuando miembros del cabildo, oficiales y religiosos, agrupados en el bando de los comuneros, se opusieron a la

5 Ver el informe del Cabildo de Asunción al Rey de 1674 en Quevedo, 1984, p. 31. 
restitución del gobierno de Diego de Reyes Balmaceda, capitulado y destituido por el gobernador interino José de Antequera (17221724), el cual defendió desde una concepción particular del derecho colonial la iniciativa local y fue condenado a muerte por sedicioso. ${ }^{6}$ En una segunda etapa, la lucha se trasladó a los tribunales de justicia y los comuneros fueron apoyados en sus reclamos por el gobernador Martín de Barúa (1725-1730), quien visito las misiones y sugirió al Rey y a su Consejo poner corregidores españoles en ellas. En la tercera y última etapa (17301735), el movimiento recobró fuerza y se radicalizó con la llegada de Mompox, (confidente y compañero de celda de Antequera), quien reavivó la lucha por el bien común y la extendió al ámbito de la campaña y los presidios. Los nuevos protagonistas fueron los cabos y miembros de las milicias rurales en quienes recaía la parte más pesada de la defensa de la frontera. Conformaron una Junta de Gobierno y se apoderaron del poder y de la justicia. Expulsaron por segunda vez de la ciudad a los jesuitas y planearon recuperar los territorios de las reducciones comprendidos entre los ríos Tebicuary y Paraná. ${ }^{7}$ Finalmente, rechazaron a dos gobernadores que llegaron a Asunción con nombramientos del Virrey y al último lo mataron. ${ }^{8}$ A continuación analizaremos el rol de las milicias guaraníes en los diferentes momentos mencionados.

Al fracasar, en 1724, las negociaciones previas para reponer a Diego Balmaceda en el gobierno, los jesuitas debieron movilizar, en secreto por orden del virrey, 2000 efectivos de las reducciones, apostarlos en las márgenes del río Tebicuary y prepararlos para el combate. Mientras aguardaban refuerzos, los asuncenos lograron movilizar un ejército superior y los derrotaron. Ese mismo año, a pedido del Virrey, prepararon una fuerza persuasiva de 6000 guaraníes, para reestablecer el gobierno, lo cual finalmente no

6 Este tema ha sido investigado por Avellaneda, 2004.

7 El bando de los "contrabandos" estaba integrado por todos los que se oponían a la expulsión de los jesuitas, dispuestos a obedecer a los enviados del virrey y a sumarse a las milicias guaraníes para reestablecer el orden político. En un principio estuvieron representados por el obispo del Paraguay y parte del cabildo eclesiástico, una minoría de encomenderos, algunos parientes del gobernador Diego de Reyes, algunos miembros del cabildo secular y los habitantes de Villa Rica quienes mantenían relaciones comerciales con las reducciones.

8 En la tercera etapa se produjeron fracturas al interior del movimiento por el incremento de la violencia con el asesinato del gobernador Ruiloba y el acaparamiento de encomiendas y bienes por el descontrol reinante. Muchos comuneros de la primera hora se pasaron al bando realista cuando el gobernador de Buenos Aires se encargó personalmente en 1735 de juntar un ejército importante de leales para entrar en la Provincia y retomar el poder. 
entró en acción. Como recompensa y ante la inseguridad instalada en las misiones por la derrota en el río Tebicuary, la Compañía de Jesús logro obtener, en 1726, una Cédula Real que ponía fuera de la jurisdicción del Paraguay a sus reducciones. Esta situación, que de hecho retraía la frontera de la provincia al sur del río Tebicuary, junto con los nuevos gravámenes punitorios impuestos al comercio de Paraguay para financiar la defensa del puerto de Santa Fe, profundizaron, aún más, las tensiones. En 1732, con la expulsión de los jesuitas de Asunción, las reducciones se prepararon para resistir una posible invasión. Durante un año movilizaron 7000 guaraníes para hacer alarde de fuerza, controlar los pasos del río Tebicuary y ocupar una línea defensiva que mantuvo a partir de entonces la ciudad de Asunción aislada y su comercio paralizado. En un intento de pacificar la provincia y ante las numerosas quejas de los vecinos por los abusos cometidos, intervino el obispo de Paraguay y logró el regreso de las milicias a las reducciones. Pero el asesinato del gobernador Ruiloba, a fines del 1733, dio lugar a un nuevo rearme general de las milicias de las reducciones y al breve levantamiento de los correntinos que simpatizaban con los comuneros. Cumpliendo nuevas órdenes del virrey Salvatierra, el gobernador del Río de la Plata Bruno de Zavala recuperó, en 1735, el gobierno del Paraguay con la ayuda de 6000 mil guaraníes y 100 dragones del puerto de Buenos Aires. En recompensa por todos los servicios brindados, las milicias y los jesuitas obtuvieron de Zavala informes elogiosos y un petitorio para que no se les retirase el privilegio a las reducciones de poseer armas de fuego para su defensa.

\section{Gobernación del Río de la Plata}

La gobernación del Río de la Plata (Buenos Aires, Corrientes, Santa Fe y Montevideo) también tuvo una dinámica fronteriza compleja que se manifestó en varios frentes de choque externo y resistencia interna, durante los siglos XVII y XVIII. El miedo permanente a una posible invasión de Buenos Aires por flotas extranjeras, el avance portugués sobre el Río de la Plata y los continuos ataques de los indígenas gentiles a las ciudades y estancias españolas, configuraron un espacio de interacción particular signado por el permanente estado de alerta. Esta situación entraba en contradicción con la vulnerable fuerza militar de los pueblos de encomienda de Asunción y Villarrica y de los vecinos y encomenderos hispano-criollos, en quienes - en una primera instancia - 
recayó la defensa de la tierra conquistada y la expansión hacia territorios aún no dominados en virtud del pacto de vasallaje con la corona y las obligaciones y derechos derivados del mismo. Este esquema, como vimos fue alterado a partir de la creación de las milicias guaraníes y el reconocimiento real de su importancia geopolítica. Pero como vimos para el Paraguay, con ciertas excepciones, las milicias guaraníes constituyeron más un potencial valuarte defensivo que fuerzas ofensivas concretas. Por su parte en la gobernación de Buenos Aires, el proceso tampoco fue lineal ya que los resultados bélicos de las milicias guaraníes no fueron parejos en todos los flancos, la Corona se mantuvo ambigua en su política de defensa, básicamente, en relación con la penetración portuguesa en su territorio colonial y, además, en el medio local se desplegaron alianzas político-económicas independientes de los intereses reales afectando la consolidación de una política de defensa homogénea. Ahora bien, veamos en que situaciones intervinieron las milicias guaraníes en la gobernación del Río de la Plata, a lo largo de los siglos XVII y XVIII, de qué manera y cuáles fueron los resultados.

Suministro de soldados guaraníes para desalojar a portugueses instalados en estancias, vaquerías o poblaciones fortificadas en territorio de la gobernación. Luego de una primera etapa signada por los ataques bandeirantes, ${ }^{9}$ el avance portugués cobró vida a través del impulso dado por el rey de Portugal y sus gobernadores de Río de Janeiro. Esta vez, el mecanismo de expansión se centró en la fundación de núcleos de población fortificados para colonizar la tierra y participar de los réditos económicos que daba la comercialización de las riquezas ganaderas de la Banda Oriental. ${ }^{10} \mathrm{Al}$ enclave de Colonia de Sacramento, fundado en 1680 sobre

9 En el contexto de la unión de las Coronas de España y Portugal en la persona de Felipe II e inmediatamente después de la fundación de Buenos Aires, el Río de la Plata experimento las primeras bandeiras luso-brasileras, asociaciones entre paulistas en colaboración con los tupí que azolaron la región hasta la década de 1640, en búsqueda de mano de obra indígena para esclavizar. Esto dio inicio a un período irreversible de expansionismo lusitano sobre la línea de Tordesillas con pérdidas de territorios y súbditos para España. Dos factores contribuyeron en la disminución de las entradas de bandeirantes paulistas a la región después de 1640. Uno de ellos fue el impacto de la creación del ejército guaraní con autorización al uso de armas de fuego. Otro fue consecuencia de que, tras los réditos obtenidos por la explotación de los minerales de Minas Gerais, los paulistas concentraron su atención en la actividad minera y sus ganancias les permitieron saciar sus requerimientos de mano de obra con la compra de esclavos negros (Mörner, 1986 [1953]).

10 Por entonces Portugal enfrentaba serias dificultades económicas como producto de la declinación del precio del azúcar y otros productos brasileros, por lo que perse- 
el Río de la Plata frente a Buenos Aires, se sumaron Laguna, en 1686, y Río Grande, en 1737, sobre territorio en teoría de la Corona española. La política esbozada desde el contexto local, se manifestó en los desalojos y sitios de Colonia de Sacramento, realizados en 1680, 1705 y 1735, por los gobernadores de Buenos Aires y las milicias guaraníes. En estas tres oportunidades los superiores jesuitas autorizaron el envío de un promedio de 3000 soldados, aproximadamente.

En las dos primeras tomas de la fortaleza lusitana, el ejército hispano-guaraní sorprendió con una fuerza militar sólida en sus objetivos, mientras que la violencia desplegada por los guaraníes en el campo de batalla y los excesos cometidos con los prisioneros aterrorizó a los portugueses de Colonia (Neumann, 2000). No obstante, guaraníes y portugueses también encontraron instancias de intercambios de bienes mientras los milicianos permanecieron en el lugar. Estas dos facetas formaban parte de un entramado de tradiciones bélicas resignificadas en el contexto colonial. Al respecto, las instancias bélicas eran, para los guaraníes reducidos, oportunidades de venganza y de descompresión de la rutina misional, que se expresaban a través de la violencia sin límites, los tratos a escondidas de los gobernadores y las fugas a espaldas de los jesuitas (Susnik, 1983). Estas situaciones de descontrol preocupaban a las autoridades y a los misioneros, sin embargo, premeditadamente los gobernadores buscaron canalizar esa violencia en el enfrentamiento con el enemigo.

Finalmente, las milicias guaraníes lograron contralor los enfrentamientos bélicos en las tomas de Sacramento mientras fueron efectivo el uso de caballos y los combates cuerpo a cuerpo. En cambio, cuando se multiplicaron las armas de fuego, las flotas de guerra y la artillería de campaña, las tropas guaraníes perdieron el dominio de las situaciones y, además, los conflictos internos sumaron inestabilidad a la ofensiva. Esto ocurrió durante la tercera y última toma a Colonia de Sacramento, en 1735. En esta oportunidad, el ejército hispano-guaraní, que venía de terminar una larga lucha contra los "comuneros" del Paraguay, acudió a la toma para realizar el asalto pero los caciques guaraníes se negaron a permanecer largo tiempo sitiando la fortaleza y en su lugar quedaron cinco fragatas de guerra. Los portugueses resistieron ayudados por 
once barcos de guerra enviados desde Lisboa y Río de Janeiro. ${ }^{11}$ Fue entonces que las milicias se enfrentaron con sus primeras limitaciones en el campo de batalla y en el futuro no fueron convocadas, por las autoridades porteñas, para un enfrentamiento de tales dimensiones.

Provisión temporaria de guaraníes reducidos para trabajar en la fortificación y defensa del Puerto de Buenos Aires frente a una posible invasión extranjera por vía fluvial. El temor a la llegada de flotas enemigas estuvo presente en el imaginario de la sociedad colonial desde sus primeros tiempos. Así, previamente a la instalación de los portugueses en Colonia se realizó una Junta de Guerra de Indias, en Madrid, para esbozar una estrategia de defensa del Puerto. Entre las propuestas presentadas se consideró, en 1672, la posibilidad de trasladar 1000 familias guaraníes e instarlas permanentemente en Buenos Aires. Dos años después, el cabildo de Santa Fe solicitó el traslado de una reducción jesuita a su jurisdicción con objetivos de defensa. Ante las diversas presiones, en 1680, una real Cédula ordenó el traslado de las familias a Buenos Aires, pero los jesuitas lograron revertir la misma (Mörner [1953] 1986). En cambio, se concilió, a partir de 1688, el envío de milicias para el reconocimiento anual de la costa del Río de la Plata y para trabajar en la fortificación de Buenos Aires. Ocasionalmente, estas debieron prepararse para una posible invasión al Puerto. Así, en 1697, se enviaron 2000 soldados ante las noticias de la llegada de flotas francesas y, en 1700, otros 2000 frente a rumores de la presencia de navíos dinamarqueses (Furlong, 1962). Pero nunca se produjo un enfrentamiento de estas características por lo que las milicias guaraníticas constituyeron, al respecto, más que nada una base de apoyo y tranquilidad, para las autoridades y la sociedad porteña, que una fuerza de choque real contra una invasión externa.

Envío de soldados guaraníes como tropas auxiliares en las guerras de pacificación y exterminio de los indios infieles. En la gobernación del Río de la Plata, las milicias guaraníes tuvieron un rol menor en la "pacificación" de los grupos nómades y gentiles. Aquellas fueron convocadas, por primera vez, a mediados del siglo XVII, como tropas auxiliares contra los calchaquíes e indios "frentones" que hostigaban Santa Fe y Corrientes, pocos años antes de la "Gran Rebelión" que encabezaron las parcialidades indígenas

11 Biblioteca Pública de Nueva York. Rich Collection. Microfilme, rollo 85. "Extracto sucinto de los asuntos comprendidos en los tres resúmenes generales de la expedición de la Colonia de Sacramento", sin fecha. 
nombradas en primer lugar. En aquella oportunidad, las misiones guaraníes contribuyeron con dos envíos de 350 soldados, en calidad de socorro a las tropas encabezadas por los vecinos españoles. ${ }^{12}$ En 1702, los guaraníes reducidos se involucraron, nuevamente, en un enfrentamiento con parcialidades charrúas coaligadas con yarros y bohames. Sin embargo, en esta oportunidad la guerra declarada a estas últimas surgía, básicamente, de cuestiones que afectaban directamente a las misiones jesuíticas. Al respecto, la expansión ganadera de las misiones guaraníes sobre área de influencia de los charrúas había sido resistida por estos grupos a través de una seguidilla de asaltos a las estancias y agravios sobre las reducciones (Bracco, 2004 y Maeder, 1992). Ante el fracaso de las negociaciones, las autoridades jesuitas solicitaron la intervención del gobernador de Buenos Aires mientras enviaban un ejército de las misiones - comandado por un sargento español y seis jesuitas, auxiliados por caciques guenoas - para hacer frente a los charrúas coaligados. Sin el consentimiento de las autoridades porteñas, las milicias guaraníes chocaron contra los charrúas, en febrero de 1702, en el combate del Yí hasta someterlos temporariamente, ya que nuevas campañas se realizaron en el año 1715 y en 1749.13

En términos generales, los gobernadores del Río de la Plata solicitaron las milicias guaraníes básicamente para la defensa del territorio contra el dominio extranjero y los superiores respondieron a la mayoría de las convocatorias registradas en la documentación. Por actuar con frecuencia en las campañas militares las misiones eran elogiadas por las autoridades españolas. A nivel personal, los guerreros más disciplinados y destacados en el campo de batalla eran recompensados con honores y cargos vitalicios. En lo que hace a las reducciones, el éxito y disposición de las milicias entraba en una pulseada de contraprestaciones y exenciones tramitadas por los procuradores jesuitas ante el Rey. Dentro de este juego, los jesuitas lograron revertir, después del desalojo de Sacramento, una Cédula Real que ordenaba el traslado de 1.000 familias a Buenos Aires. Pocos años después, obtuvieron obvenciones en el terreno económico ya que la Corona desvinculó al tráfico misionero del pago de Sisa, impuesto al comercio creado para sostener la defensa militar del territorio. ${ }^{14}$ También, lograron mantener la

12 "Memorial del P. Jerónimo Herrán, procurador General de la provincia del Paraguay, a su Majestad, año 1726" (Pastells, Tomo VII, 1912).

13 Archivo General de la Nación (Buenos Aires). Sala XI. Compañía de Jesús, Legajo 610-1.

14 Además contribuyeron a la obtención de provisiones, en beneficio de las reducciones jesuíticas, el rol económico ocupado por la estructura financiera local de la 
reducción en el pago del tributo y exenciones en el pago del diezmo. Finalmente, los jesuitas evitaron el nombramiento de corregidores españoles en los pueblos, manteniendo una estructura de gobierno interno basado en un cabildo con autoridades indígenas controlado por los misioneros. Sin embargo, la participación de las milicias también tuvo su costado negativo ya que implicaba desgastes y pérdidas humanas y materiales. A su vez, esta situación tuvo su quiebre en la década de 1750, como veremos en las siguientes páginas.

\begin{tabular}{|c|c|}
\hline \multicolumn{2}{|c|}{$\begin{array}{c}\text { CUADRO } 1 \\
\text { EFECTOS DE LA ACTUACION DE LAS MILICIAS } \\
\text { EN EL BIENESTAR DE LAS MISIONES }\end{array}$} \\
\hline $\begin{array}{l}\text { PRIVILEGIOS Y } \\
\text { RECONOCIMIENTOS }\end{array}$ & $\begin{array}{c}\text { CONSECUENCIAS } \\
\text { NEGATIVAS }\end{array}$ \\
\hline $\begin{array}{l}\text { * Exenciones en impuestos } \\
\text { (alcabala, diezmos y sisa) y } \\
\text { reducción del tributo, que } \\
\text { tuvieron su repercusión positiva } \\
\text { en la economía misionera } \\
\text { * Caciques guaraníes destacados en } \\
\text { el campo de batalla fueron re- } \\
\text { compensados con honores y car- } \\
\text { gos vitalicios. } \\
\text { * La Compañía de Jesús obtiene de } \\
\text { la Corona que todas sus reduc- } \\
\text { ciones pasen a la jurisdicción de } \\
\text { Buenos Aires. } \\
\text { * Las misiones revierten los } \\
\text { intentos de las autoridades } \\
\text { políticas y eclesiásticas locales de } \\
\text { incluir corregidores españoles en } \\
\text { su administración y aumentar el } \\
\text { tributo. } \\
\text { * Los jesuitas logran evitar que se } \\
\text { trasladen permanentemente fami- } \\
\text { lias guaraníes a los puntos estra- } \\
\text { tégicos de defensa . }\end{array}$ & $\begin{array}{l}\text { * Los privilegios concedidos genera- } \\
\text { ban nuevas obligaciones y compro- } \\
\text { misos de participación de las mili- } \\
\text { cias. } \\
\text { * Tras la salida de soldados guaraníes } \\
\text { de las misiones se producían bajas } \\
\text { demográficas por muertes o por de- } \\
\text { serciones. } \\
\text { * Inversión y pérdida de recursos } \\
\text { materiales de las misiones para or- } \\
\text { ganizar los enfrentamientos } \\
\text { * Inexistencia de un sueldo o recom- } \\
\text { pensa material a los soldados guara- } \\
\text { níes, prometida por las autoridades } \\
\text { coloniales. }\end{array}$ \\
\hline
\end{tabular}

Compañía de Jesús. Al respecto, los colegios eran solicitados por vecinos particulares para préstamos y asesorías político-económicas, además de mantener conjuntamente redes de comercio. 


\begin{tabular}{|c|c|}
\hline $\begin{array}{r}\text { CU/ } \\
\text { EFECTOS DE LA ACTL } \\
\text { EN LA DEFENSA DE LA FRONTER }\end{array}$ & $\begin{array}{l}\text { ORO } 2 \\
\text { ICION DE LAS MILICIAS } \\
\text { Y EN LAS RELACIONES POLITICAS }\end{array}$ \\
\hline DEFENSA FRONTERA & RELACIONES POLÍTICAS \\
\hline $\begin{array}{l}\text { En el Paraguay, } \\
\text { - No logran controlarse totalmente } \\
\text { los ataques de los bandeirantes } \\
\text { - Se pierden pueblos de misiones } \\
\text { - A lo largo del siglo XVII y XVIII, } \\
\text { hay una retracción de la frontera } \\
\text { definida a principios del XVII. } \\
\text { - Las milicias resultan efectivas } \\
\text { contra los asunceños levantados } \\
\text { contra el poder real. }\end{array}$ & $\begin{array}{l}\text { En el Paraguay, } \\
\text { - Los privilegios concedidos a las } \\
\text { misiones, por sus milicias, generaran } \\
\text { resentimientos entre los vecinos } \\
\text { asunceños y correntinos } \\
\text { - Estos recelos condimentaron un } \\
\text { enfrentamiento con las misiones de } \\
\text { grandes dimensiones. }\end{array}$ \\
\hline $\begin{array}{l}\text { En Buenos Aires, } \\
\text { - Las milicias no logran frenar el } \\
\text { avance portugués sobre el Río de } \\
\text { la Plata } \\
\text { - En cuanto a la defensa del Puerto, } \\
\text { generan más que nada un efecto } \\
\text { de tranquilidad ante una posible } \\
\text { invasión } \\
\text { - Las milicias guaraníes fueron } \\
\text { efectivas como auxiliares en la } \\
\text { pacificación de los infieles, pero a } \\
\text { la larga esta se concretará sin su } \\
\text { participación. }\end{array}$ & $\begin{array}{l}\text { En Buenos Aires, } \\
\text { - La participación de las milicias en } \\
\text { esta gobernación se inserta dentro de } \\
\text { una red de relaciones más compleja } \\
\text { con sus gobernadores, que tiene } \\
\text { también su lugar en el terreno } \\
\text { económico. } \\
\text { - Las milicias responden de manera } \\
\text { más eficiente a los pedidos de los } \\
\text { gobernadores del Río de la Plata y } \\
\text { estos avalan a las misiones ante el } \\
\text { pedido de privilegios y reconocimi- } \\
\text { entos reales. }\end{array}$ \\
\hline
\end{tabular}

\section{Un punto de inflexión: el enfrentamiento guaraní contra las tropas luso-españolas}

En 1750, la corona de España presionada por la situación política y militar europea firmó dos tratados que beneficiaban a Inglaterra y Portugal, respectivamente. En el caso de la primera, Fernando VI concedió nuevamente los privilegios para introducir esclavos negros en América por cuatro años, mientras que con Portugal firmó un Tratado de Permuta de territorios con el objetivo de definir las fronteras de sus dominios coloniales en permanente guerra. En lo que respecta a la jurisdicción de Buenos Aires, el Tratado imponía intercambiar Colonia de Sacramento, en manos 
portugueses, y obtener el uso exclusivo del Río de la Plata por el territorio entre el Ibicuy y el Uruguay, donde estaban ubicadas siete reducciones guaraníes. La desventaja de estos Tratados para España llevó a que Carlos III, tras asumir el trono, los anulara en 1761. Sin embargo, las consecuencias fueron irreversibles desde el punto de vista económico y geopolítico ya que los ingleses consolidaron, desde el Río de la Plata, un redituable comercio para las arcas metropolitanas y finalmente, hacia principios del siglo XIX, los lusitanos del Brasil avanzaron sobre el territorio cedido por España, en 1750, luego de varias negociaciones y guerras. En lo que aquí respecta interesa detenernos en el enfrentamiento desatado entre los guaraníes reducidos y las tropas luso-españolas, tras la firma del Tratado de Permuta de $1750 .{ }^{15}$

Cuando las noticias del Tratado de 1750 llegaron al Río de la Plata, en un primer momento las autoridades locales, en su mayoría, tomaron partido en contra del mismo. Sin embargo, una vez que la Corona reafirmó el cumplimiento de las consignas del Tratado, en un contexto ideológico-político de ascendente regalismo, aquellas se alinearon contra los pueblos indígenas rebeldes. Estos, que tras la resistencia a dejar sus pueblos fueron declarados "traidores” al Rey, no se amedrentaron ante la declaración de guerra realizada por los ejércitos de España y Portugal. Los enfrentamientos bélicos más importantes entre las tropas indígenas y los ejércitos reales se concentraron en 1754 y principios de 1756. Los pueblos afectados, auxiliados por reducciones de la banda occidental del Uruguay y algunos caciques charrúas, guenoas y minuanes, resistieron el avance del enemigo sobre su territorio mientras no se produjeron enfrentamientos entre las tropas de uno y otro ejército. ${ }^{16}$ En cambio en el campo de batalla los guaraníes no pudieron

15 A diferencia de las rebeliones indígenas andinas del siglo XVIII, la disquisición sobre el rol de los jesuitas en la rebelión opacó la participación de los indígenas en la construcción de la resistencia y en la organización de la guerra. Con excepción de un puñado de investigadores, la mayoría de los especialistas no indagó en la dinámica política interna de los pueblos durante el conflicto, reproduciendo la imagen legada por los documentos jesuitas y anti-jesuitas. Entre los autores jesuitas puede citarse a Díaz y Furlong (1939), Kratz (1954) y Mateos S. J (1949 y 1951). La historiografía no jesuita sobre los conflcitos de frontera y la guerra guaranítica esta representada por Arteaga (1999), Becker (1983 y 1987), Alden (2001), Barcelos (2000), Camargo (2003), Corrales Elhordoy (1989), Maeder (1986), Martínez Martín (1998), Mörner (1961) y Neumann (2000), entre otros. Por último, se puede mencionar a autores que han buscado recuperar la agencia indígena en el conflicto tales como Ganson (2003), Hernández (1996), Maeder (1991-1992), Neumann (2004) y Wilde (2003). Este último autor se constituye en el principal referente de nuestro trabajo.

16 Los pueblos de Concepción, Santo Tomé, Cruz, Santos Apóstoles, San Carlos, San José, San Javier, Yapeyú, Santa María y Santos Mártires prestaron tropas auxiliares en el trascurso de la guerra. Además, parcialidades de naciones no reducidas, que 
dominar a su rival, perdiendo muchas vidas. ¿Cómo puede interpretarse este des-balance de fuerzas teniendo en cuenta que durante un siglo de enfrentamientos coloniales las tropas guaraníes habían sido las elogiadas milicias del Rey?

Dado los resultados bélicos podría interpretarse, ligeramente, que el ejercito comandado por Andonaegui y el portugués Gomez Freire de Andrada, como general auxiliar, gozaban de gran preparación en las nuevas técnicas militares y contaban con una tropa estable y remunerada de acuerdo a sus rangos y habilidades. Sin embargo, el ejército español muy lejos aún estaba de conformar una milicia hispano-criolla sólida capaz de reclutar y movilizar hasta 6000 soldados, como era el caso de las milicias guaraníes. En lo que respecta al ejército luso-brasilero, igual que el español, estaba formada a partir de los tres elementos básicos de la milicia europea del siglo XVIII: artillería, caballería e infantería. La verticalidad del comando y la organización jerárquica, complementada por un adiestramiento uniformado, tuvieron su expresión en la marcha geométricamente articulada y en la distribución espacial al interior de los campamentos. A su paso, el ejército atraía aventureros paulistas, lagunistas o paranaenses hábiles contra las tradicionales escaramuzas de los guaraníes (Golin, 1997 y 1999). Los portugueses conocían, más que ninguno, a los guaraníes de las misiones como rivales; conocían sus tácticas de guerra, su forma de negociar, el carácter transitorio de sus treguas así como sus debilidades por los intercambios y las ferias organizadas en los campamentos de los soldados. ${ }^{17}$ En este sentido, la captación de este conocimiento y el despliegue de prácticas ligadas a este, junto con la acción determinante del ejército español dirigido por Andonaegui resultó avasallante y jaqueo la guerra defensiva y de recursos desplegada por los caciques y comandantes guaraníes. ${ }^{18}$

Al observar el comportamiento de las tropas indígenas, a partir de las crónicas de Tadeo Henis (1836 [1768]) y Bernardo Nusdorffer (1969 [1752-1754]), de los interrogatorios y de cierta

habitaban en las proximidades del territorio de las treinta reducciones guaraníes, se sumaron a la resistencia prestando apoyo para los enfrentamientos bélicos.

17 Los portugueses, en términos generales, mantuvieron una política de intercambio con los pueblos guaraníes, incluso, en tiempos de guerra. Como parte de una estrategia de seducción y negociación levantaban "ferias" en sus campamentos para atraer la atención de los soldados indígenas e intercambiar bienes de interés recíproco.

18 En virtud de las visitas a las reducciones por las autoridades porteñas se conocía la disposición de armas en los depósitos de los pueblos. Por eso el gobernador de Buenos Aires sabía que los guaraníes no podrían disponer de un número relevante de armas de fuego para enfrentar con éxito a su ejército (Rafael Carbonell de Maisy S. J. - comentario personal). 
correspondencia existente, ${ }^{19}$ lo primero que se observa es la oposición entre una marcha coordinada, jerárquica y de gran despliegue del ejército luso-español frente a la fragmentación, vacilación y atrincheramiento de las tropas guaraníes y, entonces, surge la pregunta ¿qué ocurrió con aquella milicia guaraní que desalojó a los portugueses de Colonia de Sacramento y venció a los comuneros del Paraguay? Básicamente, fuera de la estructura mayor que implicó, en aquellas instancias, una comandancia mixta (española, jesuítica y guaraní), los indígenas misioneros, pese al componente ladino de sus dirigentes, revivieron sus formas tradicionales de guerrear y más que nunca se manifestó la dispersión de los soldados guaraníes, vivenciada en episodios bélicos precedentes. ${ }^{20} \mathrm{~A}$ su vez, cuestiones materiales y concepciones socio-religiosas condimentaron las actitudes de los caciques y soldados guaraníes. En cuento a lo primero, es inevitable remitirse al armamento disponible y a sus destrezas y conocimientos en el manejo de las armas de fuego. Una marcha a pie con arcos, lanzas y cañones de madera forrados de cuero y unas pocas armas de fuego, por un lado, y la utilización de los caballos para "piquetes" o para rápidas refriegas en movimiento, por el otro, no fue efectiva dadas las condiciones del terreno y en relación con la artillería e infantería, apoyada por los cuerpos de dragones y blandengues de los ejércitos ibéricos. ${ }^{21}$ Además, los soldados guaraníes debían marchar con sus ganados y volver a sus pueblos en los tiempos que exigía la agricultura, lo que sumó inestabilidad. Asimismo, desde el punto de vista político, si bien la reclusión de soldados fue importante en número, la disidencia interna perduró durante todo el conflicto.

En cuanto a lo segundo, el imaginario sobre sus propias habilidades y las del enemigo, las creencias religiosas en la justicia divina, en el poder de los ángeles celestiales transferido al campo de batalla y en la guerra como medio santificador, de valor y prestigio,

19 Existe una extensa documentación referente al episodio estudiado en los Archivos de España (Archivo Histórico Nacional de Madrid y Archivo de Simancas), en el Archivo General de la Nación (Colección Biblioteca Nacional) y el Archivo Nacional de Chile (Colección Jesuitas). Las fuentes y reservorios consultados han sido oportunamente citados en Quarleri (2005) y Quarleri (2006).

20 Dentro de las prácticas observadas entre los guaraníes de las misiones durante los episodios de guerra se encontraban la desobediencia a los comandantes españoles o jesuitas, la dispersión y fuga, la violencia contra el cuerpo del enemigo como símbolo de venganza y la captura de un botín de guerra.

21 Los guaraníes si bien eran buenos jinetes no tenían fama de manejar las armas de fuego con habilidad y Andonaegui era conciente de esto (Archivo General de la Nación (Buenos Aires), Biblioteca Nacional, Legajo 289, Documento № 4412). 
así como las incertidumbres y los engaños fueron factores fundamentales en la configuración de la defensa indígena. Los guaraníes marcharon confiados en sus objetivos, en su coraje y en la justicia de la causa, atrincherados en su territorio, disponiendo de recursos y, en teoría "hechos un cuerpo". Esta concepción bélica, basada en el espíritu de combate y en la fuerza y valentía, así como en la negociación con el enemigo seguida por la traición, chocó con aquella otra basada en la planificación y en la disciplina de inspiración occidental. Hasta último momento, los guaraníes desconocían si los ejércitos reales marcharían juntos y por ende no se prepararon contra la fuerza de ambas tropas. ${ }^{22}$ Aquí los espías, muchos de ellos "indios infieles" aliados, no informaron adecuadamente y en algunos casos traicionaron a sus paisanos, los guaraníes. Sus comandantes, nombrados para la ocasión y pese a la organización previa liderada por los cabildos y los consejos de guerra, no lograron mantener unidos a los soldados de los diferentes pueblos y, finalmente, los caciques improvisaron sus respuestas. Los ejércitos reales avanzaron, en palabras de Tau Golin, como una serpiente devoradora y las trincheras de los soldados guaraníes "fueron sus sepulcros".23 Los pueblos confiados en sus fuerzas, probablemente, no terminaron de asimilar la dimensión del conflicto $\mathrm{y}$ sin un poder unificador esperaron al enemigo en una guerra defensiva inadecuada por las condiciones del terreno, la fragmentación interna y las armas disponibles.

\section{A modo de conclusión}

Desde el punto de vista de los alcances del ejército guaraní, podemos decir que las milicias guaraníes hasta mediados del siglo XVIII, cumplieron un rol muy importante al constituirse en la fuerza militar más importante disponible en las provincias del Paraguay y Río de la Plata, sin costo alguno para la Corona. Los gobernadores de Paraguay y en mayor medida los de Buenos Aires las solicitaron, tanto para la defensa interna, como externa del territorio, para los trabajos de defensa y en menor medida como fuerza disuasiva para reestablecer la autoridad de la Corona y del Virrey en sus dominios. De acuerdo a la documentación analizada, vimos que los superiores respondieron a la mayoría de los pedidos de los gobernadores porteños y que solo se rehusaron en los casos de

22 Archivo Histórico Nacional (Madrid). Estado, Legajo 4798/2, № 346.

23 Archivo General de la Nación (Buenos Aires), Biblioteca Nacional, Legajo 341, Documento № 5673 . 
solicitud de traslados de familias en forma permanente y en alguna ocasión contra una tribu vecina. ${ }^{24} \mathrm{Si}$ analizamos el rol de las milicias desde el punto de vista geopolítico, podemos decir que en la provincia del Paraguay no lograron contener el avance de los bandeirantes y proteger las poblaciones españolas al norte y este de la jurisdicción, ni fueron de mucha ayuda para frenar los asaltos de los indios del Chaco. La perdida de pueblos de encomienda, yerbales y tierras de cultivo provocó la retractación de la frontera española, tras el avance de grupos infieles, y obligó a los asuncenos a redoblar sus esfuerzos en la defensa de la provincia. Todo ello provocó una crisis económica sin precedentes a partir de la mitad del siglo XVII, que se agravó con la depreciación del precio de la yerba. El choque de las milicias guaraníes con la sociedad asunceña, durante el gobierno de Cárdenas y luego en la época de los comuneros, arriba descripto, se produjo por los conflictos suscitados por la competencia político-bélica y económica en la defensa de la frontera y en la explotación de los recursos.

Si consideramos que las milicias se crearon y desarrollaron en el marco de alianzas múltiples con los jesuitas, los gobernadores y la Corona española, podemos decir que en un primer momento resultaron exitosas como fuerza bélica persuasiva y que los informes elogiosos de los gobernadores de Buenos Aires a la Corona tuvieron un efecto positivo tras la concesión de privilegios especiales para la economía misionera. También lo tuvieron para los caciques y guerreros guaraníes más disciplinados y destacados en el campo de batalla que fueron recompensados con honores y cargos vitalicios. Además, los caciques y soldados guaraníes vivían la salida de las reducciones como instancias de libertad y como un medio para incrementar sus privilegios como titulares de cacicazgos o miembros del cabildo indígena. Sin embargo, si analizamos sus limitaciones vemos que, con el tiempo, las milicias jesuíticas fueron una carga muy pesada para el sistema reduccional. Los privilegios obtenidos, por los servicios concedidos al Rey, obligaron, a su vez, a las milicias a colaborar con los gobernadores del Paraguay y más estrechamente con los del Río de la Plata tanto en el envío de numerosas compañías para la defensa externa, como de mano de obra y recursos para la guerra. Todo ello representaba una carga muy pesada para la economía reduccional e instancias de fuga de las misiones para los guaraníes reducidos. Al respecto, muchos optaron por fugarse de las reducciones y reinsertarse en

24 En algunas ocasiones los superiores se negaron a mandar soldados para atacar estancias levantadas por los portugueses en la jurisdicción (Mörner [1953] 1986). 
otros contextos donde podían recobrar sus prácticas tradicionales como la poligamia.

Por otra parte, las milicias contribuyeron a opacar el rol de los asuncenos en la defensa de la frontera y a profundizar los conflictos por la tierra y la mano de obra. Para modificar esta situación, los asuncenos se enfrentaron al poder colonial y a las milicias guaraníes en las épocas de Cárdenas y de los Comuneros en defensa del bien común. A pesar de ello, la Corona mantuvo su interés en las milicias guaraníes hasta mediados del siglo XVIII y castigó las manifestaciones del "común" con gravámenes a la producción de los asuncenos que afectaron el crecimiento de su economía.

Esta situación tuvo su punto de quiebre en la década de 1750 tras la falta de linealidad entre la política de la corona y los intereses de los pueblos guaraníes. Como describimos más arriba, la firma del Tratado de Permuta, las dificultades vividas por los pueblos afectados por el mismo, durante el traslado hacia la otra banda del Uruguay, y los rumores de traición por parte de los jesuitas produjeron un quiebre en las relaciones políticas entre los pueblos del Uruguay, los representantes de la Corona y las máximas autoridades de la Compañía de Jesús, mientras que se mantuvieron relaciones de colaboración y confianza con algunos misioneros jesuitas. El enfrentamiento producido tras la implementación del Tratado de Permuta puso en evidencia las contradicciones que encerraba la alianza de intereses entre los guaraníes y las autoridades coloniales. Con la imposición y las condiciones del traslado, la corona y sus representantes abandonaban el rol de protectores de los pueblos de misiones y les declaraban la guerra por considerarlos "rebeldes" al Rey. Por su parte, los pueblos levantaron un "autogobierno" y se preparaban para la guerra contra los emisarios de su Rey español, argumentando la ruptura del pacto y la falta de garantías sobre su bienestar y el acceso a nuevas tierras.

Asimismo, el enfrentamiento bélico puso en evidencia la vulnerabilidad de una milicia creada y sostenida en base a la tradiciones guerreras de los guaraníes y por medio de una estructura de comandancia mixta, indígena y española. En este sentido, las autoridades coloniales habían mantenido la defensa de la frontera con una milicia recompensada solo indirectamente con privilegios, honores y exenciones y canalizando la energía bélica de los guaraníes en los enfrentamientos. Pero no los habían dotado de armas suficientes, en gran medida porque siempre se temió un levantamiento indígena. Durante las batallas producidas dentro del territorio misionero, en 1754 y 1756, los guaraníes se encontraron despojados de la estructura de comandancia mixta, con pocas armas, 
mal informados sobre el movimiento enemigo, fragmentados políticamente, confiados en la ayuda divina y en su fuerza bélica. Por todo esto los guaraníes se encontraron frente a frente con una realidad para la cual no se habían o no estaban material y sociopolíticamente preparados $\mathrm{u}$ organizados y la derrota fue contundente.

\section{Referências Bibliograficas}

ALDEN, Dauril. The Treaty of Madrid (1750) and the Misions of Paraquaria. In: WORKSHOP ON: JESUITS AND INTERMEDIARIES IN THE EARLY MODERN WORD. Florence, 11-13 october 2001.

AVELLANEDA, Mercedes. Orígenes de la alianza jesuita-guaraní y su consolidación en el siglo XVII. Memoria Americana, Cuadernos de Etnohistoria, Buenos Aires, 8, p. 173-200, 1999.

AVELLANEDA, Mercedes. La Alianza defensiva jesuita guaraní y los conflictos suscitados en la primera parte de la Revolución de los Comuneros. Historia Paraguaya - Anuario de la Academia Paraguaya de la Historia, vol. XLIV, p. 337-400, 2004.

ARTEAGA, Juan José. Las Consecuencias del tratado de Madrid en la desarticulación de la frontera demográfica de la Banda Oriental, 1750-1761. Montevideo: Archivo General de la Nación, 1999.

BARCELOS, Artur. Os jesuítas e a ocupação do espaço platino nos séculos XVII e XVIII. Revista Complutense de Historia de América, Madrid, 26, p. 93-116, 2000.

BECKER, Felix. La guerra guaranítica desde una nueva perspectiva: historia, ficción o historiografía. Boletín Americanista, Barcelona, 32, p. 7-37, 1983.

BECKER, Félix. Un mito jesuítico: Nicolás I rey del Paraguay. Aportación al estudio del ocaso del poderío de la Compañía de Jesús en el siglo XVIII. Asunción: C. Schauman, 1987.

BLANCO, Ricardo. Montoya y su lucha por la libertad de los indios batalla de Mbororé. Tomo L. San Paulo: Edit. Enveloart, 1898.

BRACCO, Diego. Charrúas, guenoas y guaraníes. Interacción y destrucción: indígenas en el Río de la Plata. Montevideo: Linardi y Risso, 2004.

CAMARGO, Fernando. Las relaciones luso-hispánicas en torno a las Misiones Orientales del Uruguay: de los orígenes al Tratado de Madrid, 1750. Fronteras de la Historia, Bogotá, 8, p. 227-260, 2003.

CORRALES ELHORDOY, Angel. Artillería Española en Indias II. Guerra Guaranítica (1754-1756). Montevideo: S/E, 1989.

DIAZ, Adolfo y Guillermo FURLONG. El Tratado de permuta de 1750 y la actuación de los misioneros del Paraguay. Buenos Aires: Academia Literaria del Plata, 1939. 
ELLIS, Alfredo Junior. O Bandeirismo Paulista. San Paulo: Edit. Nacional, 1934. FURLONG, Guillermo S. J. Misiones y sus pueblos guaranies. Buenos Aires, 1962 GANSON, Barbara. The Guarani under Spanish Rule in the Rio de la Plata. Stanford: Stanford University Press, 2003.

GOLIN, Tau. A expedição. Imaginário artístico na conquista militar dos Sete Povos jesuíticos e guaranis. Porto Alegre: Editora Sulina, 1997.

GOLIN, Tau. A Guerra Guaranítica. Como os exércitos de Portugal e Espanha destruíram os Sete Povos dos jesuitas e indios guaranis no Rio Grande do Sul (17501761). Porto Alegre: Editora da Universidade, 1999.

HENIS, Tadeo S. J. Diario Histórico de la rebelión y Guerra de los pueblos guaraníes situados en la Costa Oriental del río Uruguay del año de 1754. Buenos Aires: Imprenta del Estado, 1836 [1768].

HERNÁNDEZ, José Luis. Los pueblos guaranies entre 1750 y 1820. Tese (Licenciatura en Historia) Facultad de Filosofía y Letras, Universidad de Buenos Aires), 1996.

KRATZ, Guillermo S. J. El tratado hispano-portugués de límites de 1750 y sus consecuencias. Estudio sobre la abolición de la Compañia de Jesús. Roma: Biblioteca Instituti Historici S. I., vol. V, 1954.

MAEDER, Ernesto. Los problemas de límites entre España y Portugal en el Río de la Plata. Cuadernos Docentes, Resistencia, 4, 1986.

MAEDER, Ernesto. ¿Pasividad guaraní? Turbulencias y defecciones en las misiones jesuíticas del Paraguay. Congreso Jesuita de Córdoba, España. Fe y Justicia, p. 157-172. 1991-1992.

MAEDER, Ernesto. El conflicto entre charrúas y guaraníes de 1700: una disputa por el espacio oriental de las misiones. Revista de la Facultad de Derecho y Ciencias Económicas y Empresariales, Madrid, 26, p. 129-144, 1992.

MATEOS, Francisco S. J. El tratado de límites entre España y Portugal de 1750 y las misiones del Paraguay (1751-1753). Missionalia Hispánica, Madrid, 17, p. 319-378, 1949.

MATEOS, Francisco S. I., La Guerra Guaranítica y las Misiones del Paraguay. Primera campaña (1753-1754). Missionalia Hispanica, Madrid, 23, p. 241-316, 1951.

MARTINEZ MARTíN, Carmen. Datos estadísticos de población sobre las misiones del Paraguay, durante la demarcación del Tratado de Límites de 1750. Revista Complutense de Historia de América, Madrid, 24, p. 249-261, 1998.

MÖRNER, Magnus. Os jesuítas espanhóis, as suas missões guaranis: rivalidade luso-espanhola pela Banda Oriental (1715-1737). Revista Portuguesa de Historia, Coimbra, 9, 1961.

MÖRNER, Magnus. Actividades políticas y económicas de los jesuitas en el Río de la Plata. Buenos Aires: Hyspamérica, 1986 [1953]. 
NEUMANN, Eduardo. Fronteira e identidade: confrontos luso-guaranis na Banda Oriental 1680-1757. Revista Complutense de Historia de América, Madrid, 26, p. 73-92, Madrid, 2000.

NEUMANN, Eduardo. Mientras volaban correos por los pueblos: autogoverno e práticas letradas nas missões Guarani - Século XVIII. Horizontes Antropológicos, Porto Alegre, 22, 2004.

NUSDORFFER, Bernardo. Tercera Parte de la Relación sobre la mudanza de los siete pueblos. Manuscritos Da Coleçao De Angelis. Do tratado de Madri à conquista dos sete povos (1750-1802). Rio de Janeiro: Biblioteca Nacional, 1969.

PASTELLS, Pablo S. J. Historia de la Compañía de Jesús en la provincia del Paraguay (Argentina, Paraguay, Uruguay, Bolivia y Brasil); según los documentos originales del Archivo General de Indias (1568-1768). Madrid: Suarez, 191249.

PORTO, Aurelio. História das Missoes Orientais do Uruguay. Rio de Janeiro: Imprensa Nacional, 1943.

QUARLERI, Lía. La Rebelión Anunciada de las misiones jesuíticas del Uruguay (1752-1756). Suplemento Antropológico XL, 2. Revista del Centro de Estudios Antropológicos, Universidad Católica de Asunción, p. 41-73, 2005.

QUARLERI, Lía. Gobierno y Liderazgo jesuítico guaraní en tiempos de guerra. Revista de Indias (en prensa). Consejo Superior de Investigaciones Científicas (CSIC), Madrid, 2006a.

QUEVEDO, Roberto. Paraguay años 1671 a 1681. Asunción: Editorial El Lector, 1984.

SHALLENBERGER, Erneldo. A Integração do Prata no Sistema Colonial. Colonialismo Interno e Missões Jesuíticas de Guayrá. Toledo: Editora Toledo, 1997.

SUSNIK, Branislava. El Rol de los Indígenas en la Formación y en la vivencia del Paraguay. Asunción: IPEN, Tomo II, p. 63, 1983.

WILDE, Guillermo. Antropología histórica del liderazgo guaraní misionero (1750-1850). Tese (Doctourado em Antropología Social), Facultad de Filosofía y Letras, Universidad de Buenos Aires, 2003. 